\title{
GnRH-Gemcitabine Conjugates for the Treatment of Androgen- Independent Prostate Cancer: Pharmacokinetic Enhancements Combined with Targeted Drug Delivery
}

Theodoros Karampelas $^{\dagger}$, Orestis Argyros ${ }^{\dagger}$, Nisar Sayyad ${ }^{\ddagger}$, Katerina Spyridaki ${ }^{\S}$, Charalampos Pappas $\$$, Kevin Morgan ${ }^{\ddagger}$, George Kolios ${ }^{\dagger}$, Robert P Millar ${ }^{\square}$, George Liapakis ${ }^{\S}$, Andreas G. Tzakos ${ }^{\ddagger}$, Demosthenes Fokas ${ }^{\circ}$, Constantin Tamvakopoulos ${ }^{*}, \dagger$

'Biomedical Research Foundation, Academy of Athens, Division of PharmacologyPharmacotechnology, Soranou Ephessiou Street 4, Athens GR-11527, Greece.

Department of Chemistry, Section of Organic Chemistry and Biochemistry, University of Ioannina, Greece.

${ }^{\S}$ Department of Pharmacology, Faculty of Medicine, University of Crete, Heraklion, Crete, Greece.

${ }^{\perp}$ Respiratory Medicine, Castle Hill Hospital, Hull York Medical School, University of Hull

"Laboratory of Pharmacology, School of Medicine, Democritus University of Thrace, Alexandroupolis, Greece.

${ }^{\square}$ Mammal Research Institute, Department of Zoology and Entomology, University of Pretoria, Pretoria, South Africa; UCT/MRC Receptor Biology Group, Institute for Infectious Diseases and Molecular Medicine, University of Cape Town, Cape Town, South Africa; and Centre for Integrative Medicine, University of Edinburgh, Edinburgh, Scotland.

${ }^{\circ}$ Laboratory of Medicinal Chemistry, Department of Materials Science and Engineering, University of Ioannina, Greece.

\section{*Address correspondence to this author at:}

Address: Division of Pharmacology-Pharmacotechnology, Biomedical Research Foundation, Academy of Athens, Soranou Efesiou 4 street, 11527, Athens, Greece. Email: ctamvakop@bioacademy.gr. Phone: +30-210-6597475. Fax: +30-210-6597545. 


\begin{abstract}
Gemcitabine, a drug with established efficacy against a number of solid tumors, has therapeutic limitations due to its rapid metabolic inactivation. The aim of this study was the development of an innovative strategy to produce a metabolically stable analogue of gemcitabine that could also be selectively delivered to prostate cancer $(\mathrm{CaP})$ cells based on cell surface expression of the Gonadotropin Releasing HormoneReceptor (GnRH-R). The synthesis and evaluation of conjugated molecules, consisting of gemcitabine linked to a GnRH agonist, is presented along with results in androgen-independent prostate cancer models. NMR and ligand binding assays were employed to verify conservation of microenvironments responsible for binding of novel GnRH-gemcitabine conjugates to the GnRH-R. In vitro cytotoxicity, cellular uptake and metabolite formation of the conjugates were examined in $\mathrm{CaP}$ cell lines. Selected conjugates were efficacious in the in vitro assays with one of them, namely GSG, displaying high antiproliferative activity in $\mathrm{CaP}$ cell lines along with significant metabolic and pharmacokinetic advantages in comparison to gemcitabine. Finally, treatment of GnRH-R positive xenografted mice with GSG, showed a significant advantage in tumor growth inhibition when compared to gemcitabine.
\end{abstract}




\section{Introduction}

Despite advancements in methods for early cancer detection and improved insights into the molecular mechanisms and treatment options, advanced prostate cancer $(\mathrm{CaP})$ remains a major health problem for the aging man. ${ }^{1,2}$ Hormonal therapy is usually the first line of defense for $\mathrm{CaP}$ treatment by using drugs that lead to chemical castration, suppression of testosterone and dihydrotestosterone (DHT) biosynthesis. ${ }^{3,4}$ The hormonal ablation approach has been achieved successfully using agonist (through desensitization) or antagonist analogue drugs, of the native Gonadotropin Releasing Hormone (GnRH). These drugs exert their effects primarily on the pituitary gland through the GnRH-R by lowering gonadotropins and downstream gonadal sex steroids. Nevertheless, in many cases after treatment, following initial tumor regression, $\mathrm{CaP}$ progresses to an androgen-independent state with poor prognosis, which presents a major challenge for the physician and the patient. ${ }^{3,5-10}$ Research on the GnRH-R has shown that its expression is not confined solely to the pituitary but that is also present in several other tissues such as prostate, breast $^{11-13}$ and the GnRH-R level of expression along with cell context is critical for cell responses to either agonist or antagonist drugs of the receptor. ${ }^{14}$ It is also well established that GnRH-R gene expression is upregulated in patients with androgenindependent $\mathrm{CaP}$, making the GnRH-R an attractive target for the design of novel and specific therapeutics. ${ }^{15}$

A modern approach to improve conventional chemotherapy is by direct targeting of chemotherapeutic agents to cancer cells in order to enhance the tumoricidal effect and reduce peripheral toxicity of a specific drug. Linking chemotherapeutic agents to ligands (small molecule or peptides) or antibodies directed towards cell surface proteins/receptors, expressed or over-expressed uniquely in cancer cells (such as the GnRH-R), provides valuable paradigms for this approach. ${ }^{16-19}$ One representative example of a cytotoxic analogue targeting the GnRH-R is AN-152, a conjugate molecule of a peptide analogue of GnRH, ([D-Lys ${ }^{6}$ ]GnRH), linked to doxorubicin. ${ }^{20}$ Other examples of molecules linked to GnRH for targeted delivery include daunorubicin ${ }^{21}$, curcumin $^{22}$ and docetaxel ${ }^{23}$. Importantly, AN-152 has been evaluated in Phase I and Phase II clinical studies in GnRH-R positive cancer patients demonstrating anticancer activity with only moderate side effects. ${ }^{24}$ A strategy of ligand conjugation to chemotherapeutic could be employed to treat bone metastases as well. Recent studies have shown that poly(ethylene glycol)paclitaxel-alendronate micelles afford significant benefits over free paclitaxel in treating breast cancer bone metastases in mouse models due to the affinity of alendronate to bone tissue. ${ }^{25}$

Gemcitabine (2', 2'- difluorodeoxycytidine, dFdC), is an established and highly potent cytotoxic drug with a broad spectrum of cancer targets including colon, lung, pancreatic, breast, bladder and ovarian cancer. ${ }^{26}$ Upon administration, gemcitabine is transported into cells by nucleoside transporters. ${ }^{27}$ Gemcitabine is then phosphorylated by cytidine kinase to gemcitabine monophosphate (dFdCMP) which is subsequently phosphorylated to gemcitabine diphosphate ( $\mathrm{dFdCDP}$ ) and gemcitabine triphosphate (dFdCTP). Gemcitabine exerts its cytotoxic action mainly through the incorporation of $\mathrm{dFdCTP}$ into the DNA strand leading to inhibition of DNA synthesis and subsequent cell apoptosis. dFdCDP also has an indirect cytotoxic effect by inhibiting ribonucleotide reductase. A major impediment related to gemcitabine efficacy is its rapid inactivation, since upon administration more than $90 \%$ of gemcitabine is converted to its inactive metabolite, 2, 2'difluorodeoxyuridine $(\mathrm{dFdU})$ and its monophosphate derivative (dFdUMP). ${ }^{28,29}$ 
Another important drawback regarding gemcitabine therapy is that after initial tumor regression, tumors develop different forms of drug resistance. The most common form of gemcitabine induced resistance is the one related to nucleoside transporter deficiency. ${ }^{29,30}$ Previous in vitro studies demonstrated that gemcitabine has exceptional antiproliferative effects in androgen-independent $\mathrm{CaP}$ cell lines ${ }^{31}$ but modest clinical benefit when tested as monotherapy or combination therapy, mainly due to its severe peripheral side effects. ${ }^{32-34}$

Many efforts aiming to enhance the therapeutic status of gemcitabine by chemical modifications have been reported. ${ }^{30}$ These modifications have been focused on either improving gemcitabine's pharmacokinetics or reducing resistance induction. For example, LY2334737, an orally bioavailable prodrug of gemcitabine, exhibited antitumor effects in preclinical models of ovarian and breast cancer when administered in metronomic doses. ${ }^{35}$

In the current study, the design of GnRH-gemcitabine conjugates was based on improving the therapeutic potential of gemcitabine as follows:

1) Reduction of gemcitabine's metabolic inactivation. It has been shown that gemcitabine prodrugs can be designed specifically to affect its interaction with cytidine deaminase, the enzyme responsible for gemcitabine's poor pharmacokinetic properties.

2) Targeted delivery. Such a strategy would be advantageous since an effective drug (gemcitabine) would be delivered to the tumor site through conjugation to a peptide with a strong affinity for a cell surface receptor over-expressed in the tumor cell.

3) Reduction of induced resistance. The suggested conjugation potentially offers gemcitabine an alternative entrance route (GnRH-R) to the cell, possibly a crucial advantage for treating tumors that develop nucleoside transporter deficiency. 


\section{Results}

\section{Design of GnRH-gemcitabine conjugates.}

Although several lipophilic amide ${ }^{30,36}$ and ester-based ${ }^{30}$ gemcitabine analogues have been described in the literature, prodrugs derived mainly through the amidation of the 4-amino group and esterification of the primary 5'-OH group, reports on gemcitabine prodrugs for targeted delivery to cancer cells and tumors have been rather limited. For example, gemcitabine amide conjugates containing folic acid ${ }^{37}$ or a DNA binding element ${ }^{38}$ as targeting moieties have been reported. Also, a gemcitabine 5'-OH ester conjugate with biotin as the targeting vector was recently described. ${ }^{39}$ However, the design of gemcitabine conjugates with receptor binding peptides for targeted delivery has not yet been explored. Herein, a series of gemcitabine conjugates with [D-Lys $\left.{ }^{6}\right]-G n R H$, an agonistic peptide with enhanced receptor binding activity, ${ }^{17}$ was designed for the selective targeting of cancer cells that over-express GnRH-Rs. The synthesis of drug-peptide conjugates for the receptormediated targeted delivery to a specific group of cells usually involves the conjugation of the drug with a targeting peptide via an appropriate linker, which could in turn facilitate the chemical or enzymatic release of the drug once the conjugate enters the cancer cells via a receptor mediated endocytosis mechanism. Amongst several functional groups employed to connect the drug to the linker, ${ }^{40}$ ester linkages have been widely utilized since the release of the drug can proceed via an enzymatic (i.e. esterase) hydrolysis of the ester bond.

Gemcitabine contains two hydroxyl groups, a primary 5'-OH and a secondary 3'$\mathrm{OH}$, which can enable the conjugation of the targeting peptide at different sites of the drug. We surmised that gemcitabine conjugates $\mathbf{3 G}$, GSG, 3G $\mathbf{2}$, and $\mathbf{G S G}_{\mathbf{2}}$ (Scheme 1 ), with ester linkages at the primary $5^{\prime}-\mathrm{OH}$ or secondary 3 '-OH group of the drug, would be suitable substrates to address the targeted delivery of gemcitabine to prostate cancer cells and tumors that over-express GnRH-Rs. If this was the case, such targeted drug delivery could enhance the efficacy of gemcitabine.

Conjugates $\mathbf{3 G}, \mathbf{G S G}, \mathbf{3 G}_{\mathbf{2}}$ and $\mathbf{G S G}_{\mathbf{2}}$ encompass subtle changes in the length of the linker (four carbons vs. five) as well as the conjugation site (primary vs. secondary hydroxyl group), which could provide insight as to how these variables govern the physicochemical and transport properties of the conjugates. The synthesis of the desired ester-linked gemcitabine conjugates commenced with Boc-protected gemcitabine analogues $\mathbf{1 a}$ and $\mathbf{1 b}$, prepared by selective protection of gemcitabine. ${ }^{41}$ Reaction of 1 a with glutaric or succinic anhydride resulted in 5'-O-gemcitabine hemiglutarate $\mathbf{2}$ and hemisuccinate $\mathbf{3}$, respectively. Similarly, treatment of $\mathbf{1 b}$ at the secondary 3 '-OH with glutaric or succinic anhydride produced hemiglutarate 4 and hemisuccinate 5, respectively. HATU mediated coupling of acids $\mathbf{2}$ and $\mathbf{3}$ with the $\varepsilon$ amino group of [D-Lys $\left.{ }^{6}\right]-G n R H$ followed by acid mediated deprotection of the Boc group, afforded bioconjugates 3G and GSG respectively. Similarly, bioconjugates $\mathbf{3 G}_{\mathbf{2}}$ and $\mathbf{G S G}_{\mathbf{2}}$ were produced from 3 '-O-hemiglutarate $\mathbf{4}$ and hemisuccinate $\mathbf{5}$, respectively (Scheme 1). 
Scheme 1. Synthesis of GnRH-gemcitabine conjugates

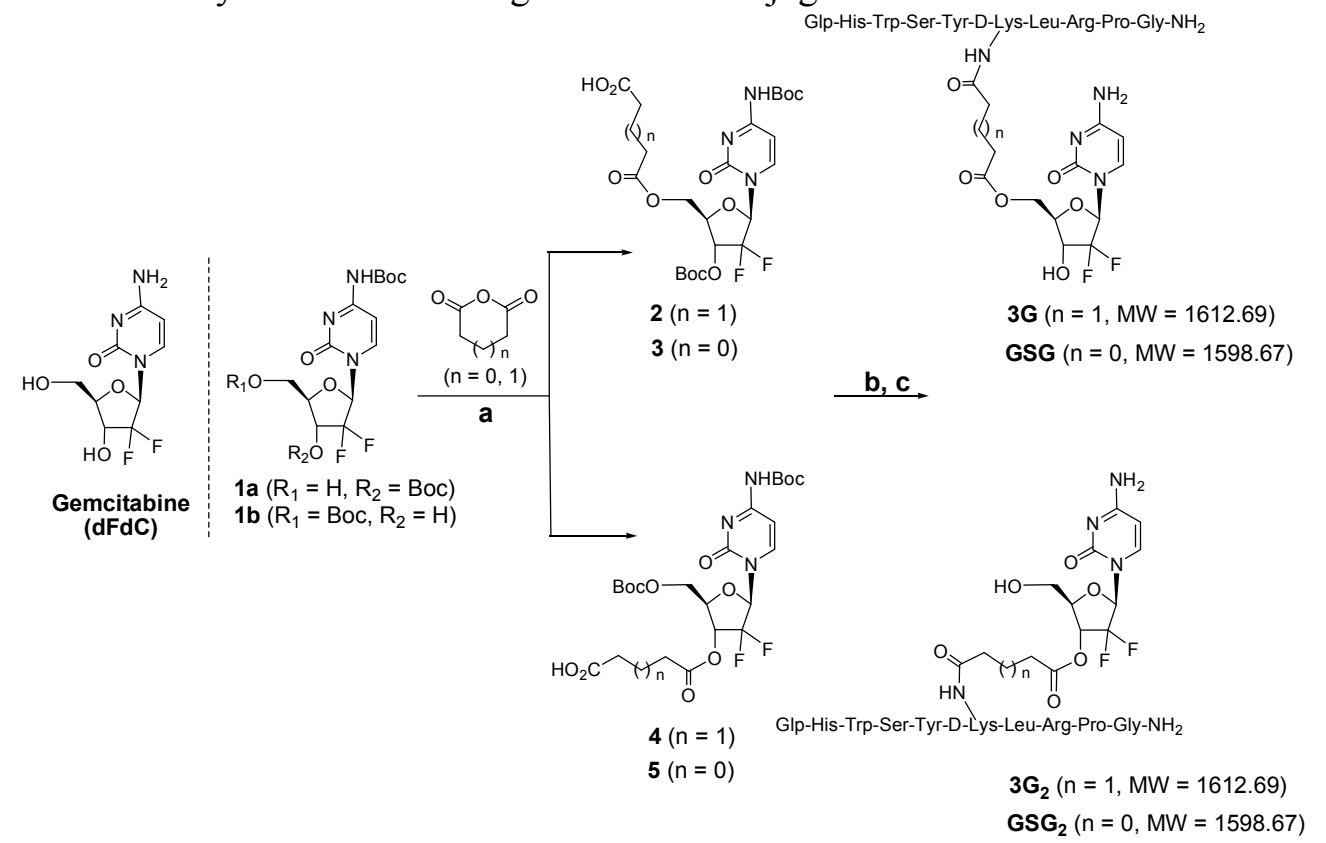

Reagents and conditions: a) $\mathrm{CH}_{2} \mathrm{Cl}_{2}, \mathrm{NiPr}{ }_{2} \mathrm{Et}, \mathrm{rt}$; b) [D-Lys ${ }^{6}$ ]-GnRH, DMF, HATU, $\mathrm{NiPr} 2 \mathrm{Et}, \mathrm{rt} ; \mathrm{c}) \mathrm{TFA}-\mathrm{H}_{2} \mathrm{O}-\mathrm{TIS}(95: 2.5: 2.5)$, rt.

Characterization of GnRH-gemcitabine conjugates. Figure 1A depicts a representative LC-MS spectrum of one of the molecules, GSG. A gradient methodology was developed that enabled simultaneous monitoring and quantification of GnRH-gemcitabine conjugate, gemcitabine as well as its inactive metabolite ( $\mathrm{dFdU}$ ) in cell cultures and mouse blood. A representative chromatogram is depicted in Figure 1B demonstrating that separation of the three analytes of interest can be achieved within a short chromatographic run time $(<5 \mathrm{~min})$.

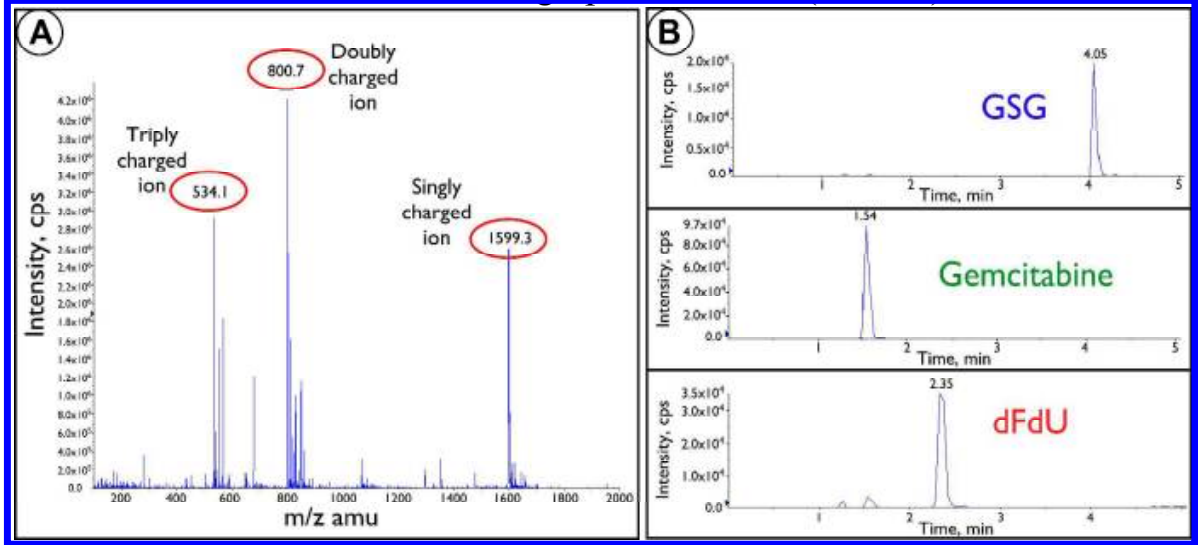

Figure 1. Design of GnRH-gemcitabine conjugates for selective delivery to GnRH-R positive cancer cells

A. Representative positive electrospray ionization (ESI $\left.{ }^{+}\right)$mass spectra of GnRHgemcitabine conjugates showing the three ionized forms (m/z 1599.3 corresponding to $\mathrm{M}+1, \mathrm{~m} / \mathrm{z} 800.7$ corresponding to $\mathrm{M}+2, \mathrm{~m} / \mathrm{z} 534.1$ corresponding to $\mathrm{M}+3$ ) of $\mathrm{GSG}$.

B. LC-MS/MS chromatogram depicts the separation of GSG, gemcitabine and dFdU.

Conjugation of gemcitabine to [D-Lys $\left.{ }^{6}\right]-G n R H$ does not alter drastically the conjugate's GnRH-R binding domains. GnRH-gemcitabine conjugates were 
evaluated by NMR. The described study allowed the assessment of potential conservation of microenvironments responsible for binding to the GnRH-R (Figure 2A). NMR studies using 2D NMR TOCSY experimentation indicate that conjugation of gemcitabine to the bioactive peptide does not perturb the chemical environment known to be important for receptor binding. The conjugation of the drug (gemcitabine) on the backbone of lysine perturbed only the chemical environment (chemical shift) of the neighboring aminoacids Leu-7 and Tyr-5 (Figure 2B), however the structure ( $\mathrm{N}$-terminus or $\mathrm{C}$-terminus) of the peptide sequence which is functionally important for receptor binding ${ }^{7,8}$ was not affected.

GnRH-gemcitabine conjugates bind to the GnRH-R with high affinities. Four GnRH-gemcitabine conjugates $\left(3 \mathrm{G}, 3 \mathrm{G}_{2}, \mathrm{GSG}, \mathrm{GSG}_{2}\right)$ were evaluated with respect to their binding potential against the GnRH-R (Figure 2C). GnRHgemcitabine conjugates bind with a high affinity to the GnRH-R ( $\mathrm{IC}_{50}$ values ranging from 1-10 nM) suggesting that these types of molecules can support the GnRH-R targeted delivery strategy. Conjugation of gemcitabine to [D-Lys $\left.{ }^{6}\right]-\mathrm{GnRH}$ does not seem to influence the binding affinity of the "homing peptide", further confirming the observations derived from the 2D-NMR experiments. The binding affinity of leuprolide and gemcitabine were evaluated in the described assays as positive and negative controls respectively ( $\mathrm{IC}_{50}$ values of $0.3 \mathrm{nM}$ for leuprolide and $>100 \mu \mathrm{M}$ for gemcitabine).

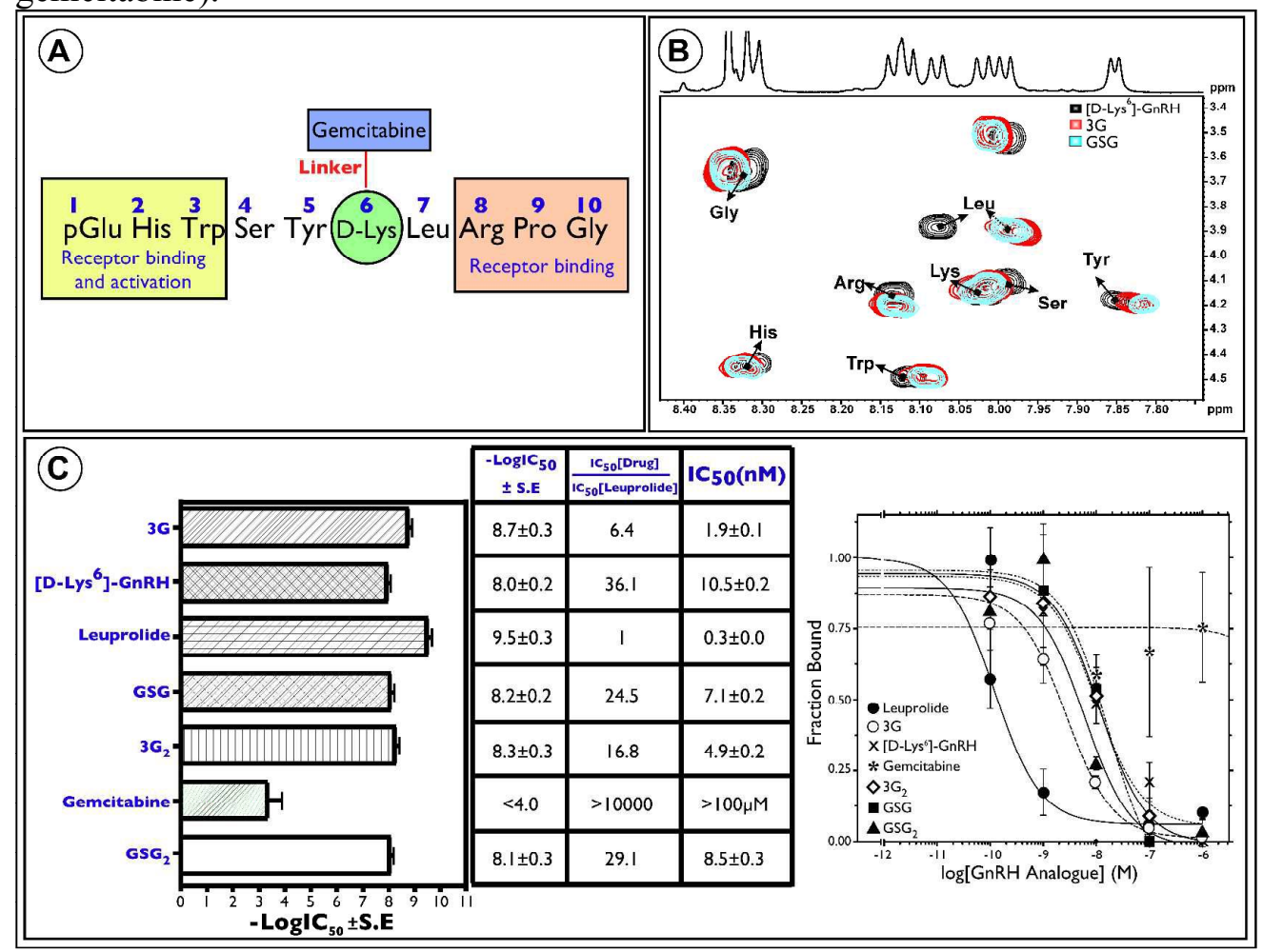

Figure 2. Evaluation of the binding potential of representative GnRHgemcitabine conjugates against the GnRH-R using 2D NMR and radioligand binding assays

A. Schematic representation of a GnRH-gemcitabine conjugate indicating the residues that are responsible for binding to the GnRH-R.

B. Superimposition of the selected region NH- of 2D NMR TOCSY spectrum of [DLys $^{6}$ ]-GnRH (black) with 3G (red) and GSG (blue). The conjugated molecules, GSG 
and $3 \mathrm{G}$ do not perturb the structure of the $\left[\mathrm{D}-\mathrm{Lys}^{6}\right]-\mathrm{GnRH}$ region that is important for binding to the GnRH-R.

C. Binding affinity $\left(\mathrm{IC}_{50}\right)$ of $\mathrm{GnRH}$-gemcitabine conjugates $(3 \mathrm{G}, \mathrm{GSG}, 3 \mathrm{G} 2$, GSG2) on the GnRH-R was evaluated in comparison to the binding affinity of the known GnRH-R superagonist leuprolide as well as the binding affinity of ([D-Lys $\left.\left.{ }^{6}\right]-G n R H\right)$. Competition binding isotherms of GnRH analogues to human GnRH - I receptor are also shown. Competition of $\left[{ }^{125} \mathrm{I}-\mathrm{D}-\mathrm{Tyr}^{6}{ }^{6}, \mathrm{His}^{5}\right] \mathrm{GnRH}$ specific binding by increasing concentrations of the analogues was performed on membranes from HEK 293 cells stably expressing the human GnRH - I receptor. The mean values and S.E. are shown from $3-4$ different experiments. The data were fit to a one - site competition model by nonlinear regression and the $\mathrm{IC}_{50}$ values were determined as described.

GnRH-gemcitabine conjugates exhibit antiproliferative potential in vitro. The antiproliferative effect of the GnRH-gemcitabine conjugates was evaluated in two androgen-independent CaP cell lines (DU145 and PC3) with gemcitabine and [DLys $^{6}$ ]-GnRH as points of reference (results shown in Table 1). GSG and $\mathrm{GSG}_{2}$ had the highest potencies which were comparable with that of gemcitabine in the examined cell lines (Average $\mathrm{IC}_{50}$ values for GSG and $\mathrm{GSG}_{2}$ of 308 and $439 \mathrm{nM}$ respectively versus $231 \mathrm{nM}$ for gemcitabine). $3 \mathrm{G}_{2}$ was also potent with an average $\mathrm{IC}_{50}$ value of $663 \mathrm{nM}$. Following stability studies in cell culture medium, GSG and $3 \mathrm{G}_{2}$ were selected for further evaluation in pharmacokinetic experiments based on the criteria of: i) sufficient stability in cell culture medium (approximately $40 \%$ of drug conjugate remaining intact following $8 \mathrm{~h}$ incubation) and ii) in vitro antiproliferative effects.

\begin{tabular}{|l|l|l|l|l|l|}
\hline $\mathbf{I C}_{\mathbf{5 0}}$ (nM) & Gemcitabine & $\mathbf{3 G}$ & $\mathbf{3 G}_{\mathbf{2}}$ & $\mathbf{G S G}$ & $\mathbf{G S G}_{\mathbf{2}}$ \\
\hline DU145 & $231 \pm 34$ & $1171 \pm 83$ & $663 \pm 273$ & $308 \pm 170$ & $439 \pm 217$ \\
\hline PC3 & $585 \pm 68$ & $1161 \pm 130$ & $729 \pm 193$ & $670 \pm 352$ & $786 \pm 125$ \\
\hline
\end{tabular}

Table 1. Antiproliferative effect of GnRH-gemcitabine conjugates in androgenindependent cell lines (PC3, DU145).

Cells were plated in 96-well plates (5,000 cells/well) and incubated for $72 \mathrm{~h}$ with either GnRH-gemcitabine conjugates or gemcitabine at selected concentrations. $\mathrm{IC}_{50}$ values shown represent means of three experiments performed in triplicates $\pm \mathrm{SD}$. [D $\left.-\mathrm{Lys}^{6}\right]-\mathrm{GnRH}$ treatment had no effect in the selected concentrations.

GSG provides enhanced systemic exposure of gemcitabine following administration in mice. Administration of GSG in mice led to blood gemcitabine concentrations averaging $500 \mathrm{ng} / \mathrm{mL}(1.7 \mu \mathrm{M})$ at $1 \mathrm{~h}$ following dosing. Importantly, levels of gemcitabine were sustainable for at least $2 \mathrm{~h}$ after dosing of GSG (average concentration: $85 \mathrm{ng} / \mathrm{mL}$ or $0.3 \mu \mathrm{M}$ ). In comparison, following equimolar dosing of gemcitabine in mice, gemcitabine was rapidly absorbed reaching highest blood concentrations averaging $685 \mathrm{ng} / \mathrm{mL}(2.3 \mu \mathrm{M})$ at $0.5 \mathrm{~h}$ following dosing. Levels of gemcitabine dropped significantly $2 \mathrm{~h}$ after dosing (average concentration: $15 \mathrm{ng} / \mathrm{mL}$ or $0.05 \mu \mathrm{M})$. In Figure $3 \mathrm{~A}$, comparative curves of gemcitabine levels are depicted, following dosing in mice of $\mathrm{GSG}, 3 \mathrm{G}_{2}$ or gemcitabine. Administration of GSG also resulted in significantly lower levels of $\mathrm{dFdU}$ in blood (Figure 3B) in comparison to gemcitabine treatment in which rapid conversion to $\mathrm{dFdU}$ was observed. The findings from the pharmacokinetic experiments suggest that administration of GSG can lead to appreciable gemcitabine formation and blood exposure $\left(\mathrm{AUC}_{15-480 \mathrm{~min}}: 4.3 \times 10^{4} \mathrm{~min} \mathrm{x}\right.$ 
$\mathrm{ng} / \mathrm{mL}$ for GSG versus $\mathrm{AUC}_{15-480 \mathrm{~min}}: 2.9 \times 10^{4} \mathrm{~min} \times \mathrm{ng} / \mathrm{mL}$ for gemcitabine) and a lower rate of formation of the inactive metabolite $\mathrm{dFdU}\left(\mathrm{AUC}_{15-480 \mathrm{~min}}: 1.8 \times 10^{6} \mathrm{~min} \mathrm{x}\right.$ area for GSG versus $\mathrm{AUC}_{15-480 \mathrm{~min}}: 4.5 \times 10^{6} \mathrm{~min} \times$ area for gemcitabine). Based on the described pharmacokinetic advantages, GSG was selected as the lead candidate compound among the $\mathrm{GnRH}$-gemcitabine coniugates for efficacy studies in mice.

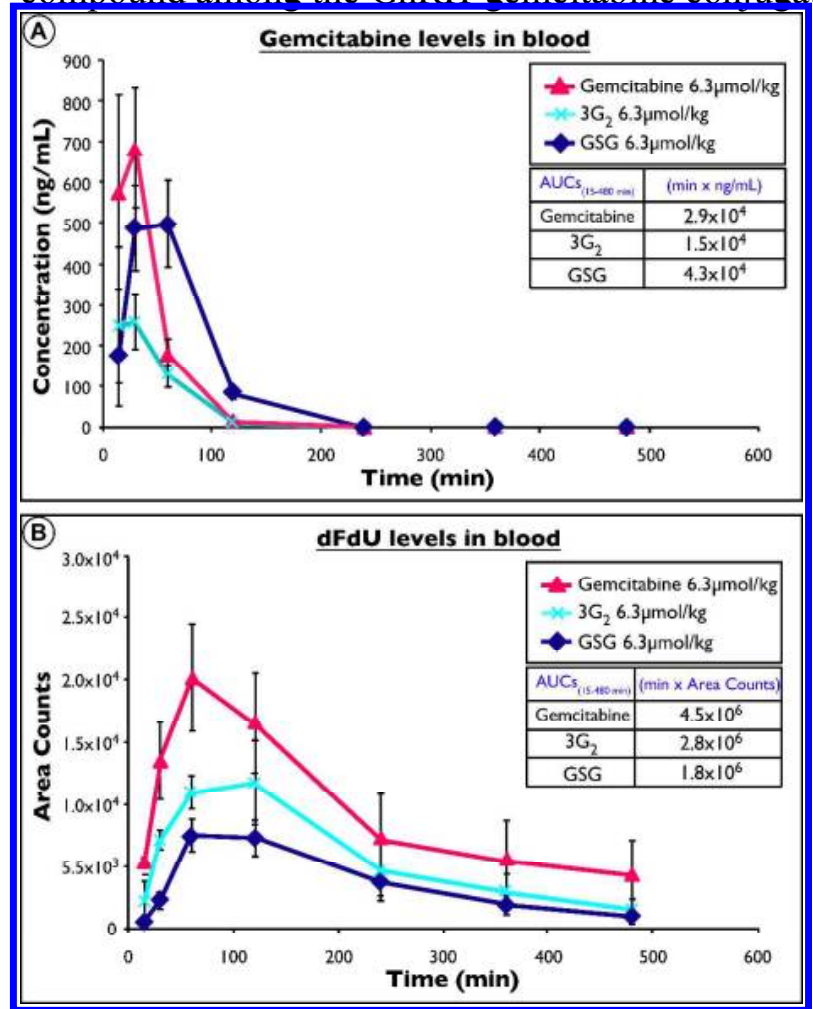

Figure 3. Pharmacokinetic evaluation of GnRH-gemcitabine conjugates versus gemcitabine

Male C57BL/6N mice $(n=5)$ were dosed (IP) with either gemcitabine, GSG, or $3 \mathrm{G}_{2}$ at a dose of $6.3 \mu \mathrm{mol} / \mathrm{kg}$ and blood samples were collected at selected time points. Gemcitabine and dFdU were monitored by LC-MS/MS. The areas under the curve (AUCs) for each treatment were calculated as a measure of gemcitabine or dFdU exposure over time.

GSG biodistribution in xenografted mice. Administration of GSG in tumor bearing NOD-SCID mice led to the following important findings: GSG has tumor bioavailability as it can be delivered at the tumor site at appreciable levels (average GSG concentration of $184 \mathrm{ng} / \mathrm{g}$ or $115 \mathrm{nM}$ at $1 \mathrm{~h})$ even at a lower dose $(6.3 \mu \mathrm{mol} / \mathrm{kg})$ in comparison to the efficacious dose $(18.8 \mu \mathrm{mol} / \mathrm{kg}$, see efficacy section). Blood level measurements of gemcitabine and $\mathrm{dFdU}$ indicated that the inactivation of gemcitabine (formation of $\mathrm{dFdU}$ ) after GSG administration was less extensive when compared to gemcitabine administration (Table 2) a finding that was consistent with pharmacokinetic experiments in naïve mice. Although this significant pharmacokinetic advantage was not as pronounced at the tumor site, a slight increase of the $\left.\mathrm{AUC}_{(0-24} \mathrm{h}\right)$ Gemcitabine:dFdU ratio was observed with GSG dosing in comparison to gemcitabine (0.016 vs. 0.013$)$. 


\begin{tabular}{|l|l|l|}
\hline $\begin{array}{l}\text { Gemcitabine:dFdU } \\
\text { AUC }_{(\mathbf{0 - 2 4} \text { h) }}\end{array}$ & $\begin{array}{l}\text { Gemcitabine } \\
\text { Administration }\end{array}$ & $\begin{array}{l}\text { GSG } \\
\text { Administration }\end{array}$ \\
\hline Blood & $\mathbf{0 . 0 2 3}$ & $\mathbf{0 . 2 0 2}$ \\
\hline Tumor & $\mathbf{0 . 0 1 3}$ & $\mathbf{0 . 0 1 6}$ \\
\hline
\end{tabular}

Table 2. Bioavailability of gemcitabine, $\mathrm{dFdU}$ in blood and tumors

GSG enters the cell and affords sustained gemcitabine levels. The expression of GnRH-R levels was confirmed in the tested CaP cell lines by Western Blot analysis (Figure 4A). The cell uptake of GSG in DU145 cells and the intracellular release of gemcitabine were evaluated in comparison to gemcitabine. Following incubation of cells with gemcitabine, gemcitabine was rapidly inactivated forming $\mathrm{dFdU}$. Incubation of GSG with cells led to a relatively slow formation of gemcitabine and what appeared to be sustained levels of gemcitabine over time (up to $8 \mathrm{~h}$ ). In contrast, incubation of gemcitabine with cells, led to higher dFdU levels in comparison to dFdU formed upon incubation of GSG, further supporting our hypothesis that GSG's efficacy could be partially based on a mechanism of action associated with a "slow down" of gemcitabine's inactivation. The ratio of the intracellular levels of gemcitabine over $\mathrm{dFdU}$ as a function of time is depicted in Figure 4B. Moreover, pre-incubation of DU145 cells for $1 \mathrm{~h}$ with $1 \mu \mathrm{M}$ [D-Lys ${ }^{6}$ ]GnRH affected the kinetics of GSG $(10 \mu \mathrm{M})$ uptake. An approximate $40 \%$ reduction in intra-cellular concentrations of GSG was measured in the pre-treated cells (data not shown), an observation that supports the hypothesis of selective GSG entrance to the cell through the GnRH-R

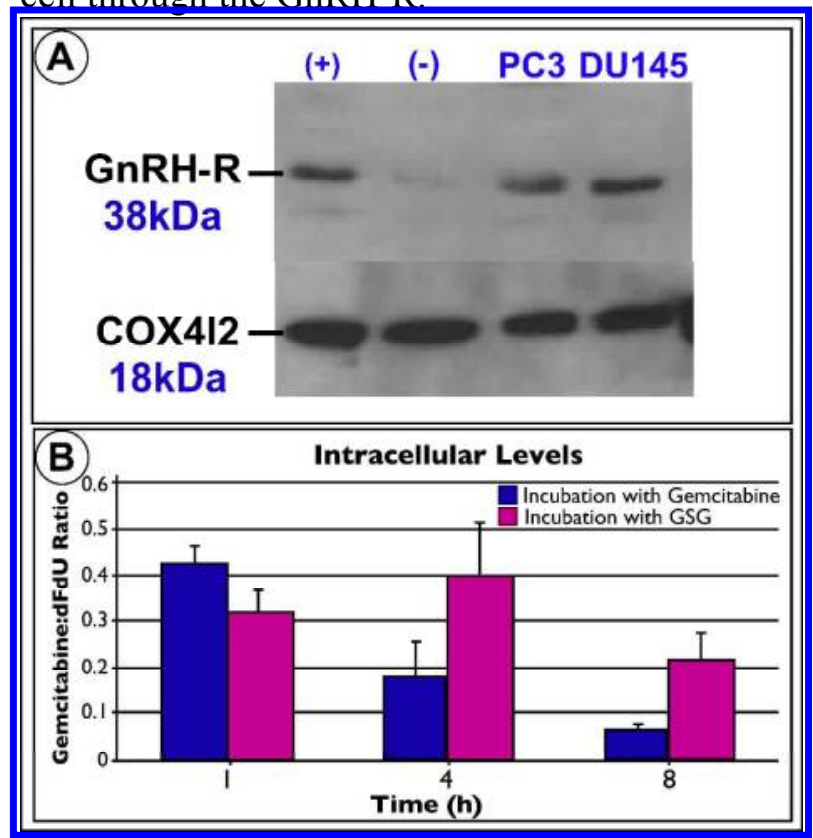

Figure 4. Cell culture GnRH-R expression and cell uptake of a GnRHgemcitabine conjugate

A. GnRH-R expression in the two androgen-independent cell lines used (DU145, PC3) for the evaluation of the antiproliferative effects of the GnRH-gemcitabine conjugates. MCF-7 and RAW264.7 cells were used as positive (+) and negative (-) controls respectively. Expression of the GnRH-R in androgen-independent cell lines was confirmed by Western blot analysis as a band at $38 \mathrm{kDa}$.

B. GSG vs. gemcitabine cell uptake in DU145 cells. Cells were incubated with $10 \mu \mathrm{M}$ 
GSG or gemcitabine for selected time points $(1 \mathrm{~h}, 4 \mathrm{~h}, 8 \mathrm{~h})$ and were then lysed in order to determine intracellular levels of gemcitabine and its inactive metabolite (dFdU) by LC-MS/MS. Experiments were performed in triplicates.

GSG inhibits tumor growth. The efficacy of GSG was tested on a GnRH-R positive prostate cancer animal model using the DU145 CaP cell line. Efficacy was compared to equimolar dose of gemcitabine or the peptide used for targeting the GnRH-R ([D-Lys $\left.\left.{ }^{6}\right]-G n R H\right)$. Pharmacokinetic studies of GSG at $6.3 \mu \mathrm{mol} / \mathrm{kg}$, demonstrated that average circulating levels of gemcitabine could reach $85 \mathrm{ng} / \mathrm{ml}$ (or $323 \mathrm{nM}$ ) at $2 \mathrm{~h}$ post-dose (see Figure 3). Evaluation on antiproliferative in vitro effects of gemcitabine in cell lines indicated that the $\mathrm{IC}_{50}$ of gemcitabine was approximately $230 \mathrm{nM}$ (see Table 1). Based on the above observations, in order to ensure an efficacious dose, the dose chosen for efficacy studies of GSG was 18.8 $\mu \mathrm{mol} / \mathrm{kg}$. A clear inhibitory effect of GSG on tumor growth was observed when compared to the control group (vehicle) or equimolar doses of gemcitabine or [DLys $^{6}$ ]-GnRH. Average tumor volume of GSG treated group at day 18 was $506 \mathrm{~mm}^{3} \pm$ 152 , significantly lower $(P<0.001)$ when compared to vehicle $\left(1266 \mathrm{~mm}^{3} \pm 421\right)$, low dose gemcitabine $\left(1110 \mathrm{~mm}^{3} \pm 270\right)$ or $\left[\mathrm{D}-\mathrm{Lys}^{6}\right]$-GnRH $\left(1030 \mathrm{~mm}^{3} \pm 290\right)$ treatments (Figure 5A). Efficacy was achieved also with a high dose of gemcitabine of 454.5 $\mu \mathrm{mol} / \mathrm{kg}$ or $120 \mathrm{mg} / \mathrm{kg}$ (tumor volume at day 18 of $482 \mathrm{~mm}^{3} \pm 198$ ). Mice treated with GSG or high dose gemcitabine showed significant $(P<0.001)$ tumor inhibition when compared to vehicle, low dose gemcitabine or [D-Lys $\left.{ }^{6}\right]-\mathrm{GnRH}$ treatments, measured as area under the tumor volume - time curve (AUC) until day 18 (Figure 5B). No morbidity or significant changes in body weight were observed in the animals during the course of the experiment. suggesting that all the treatments were well tolerated.

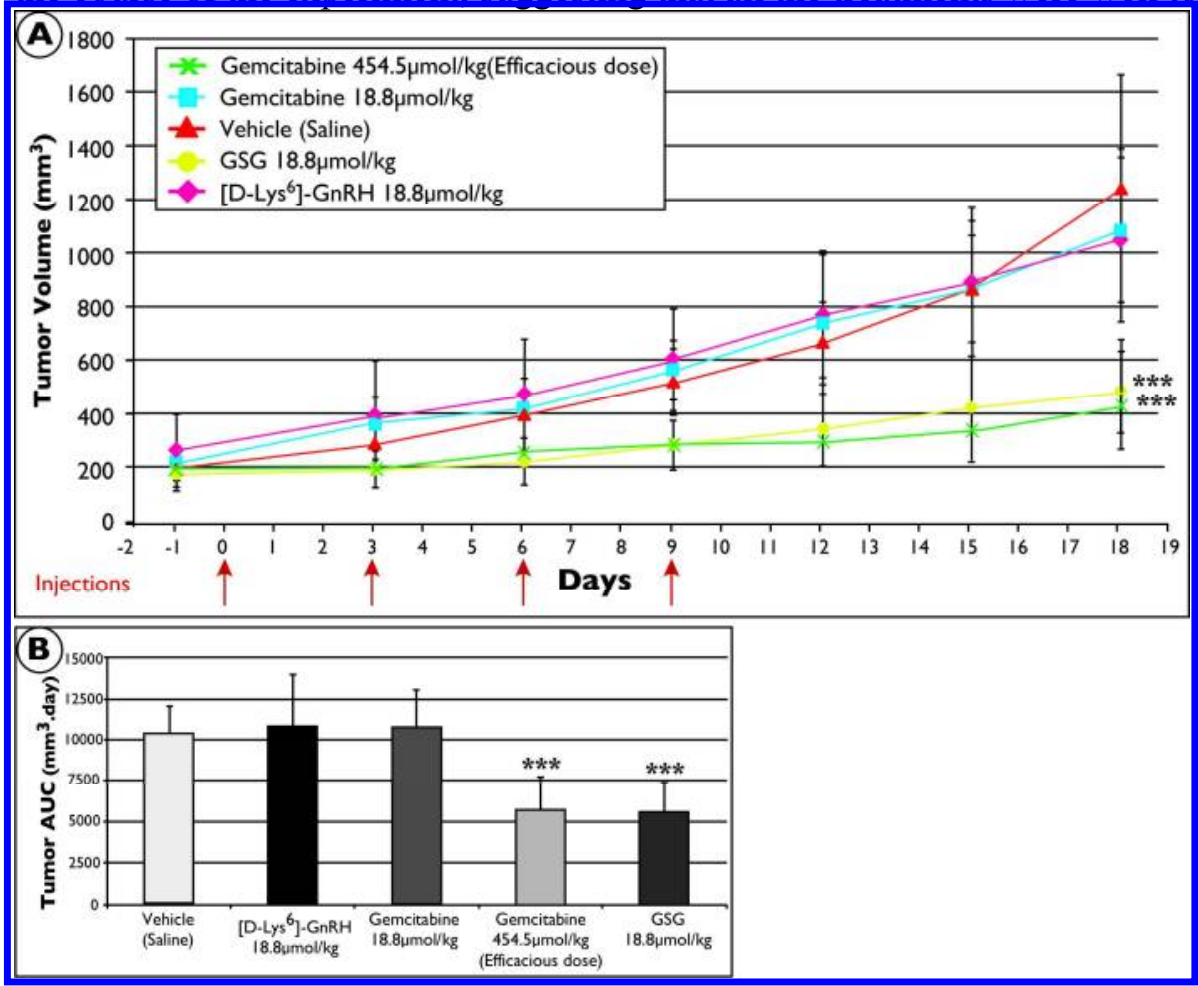

Figure 5. Therapeutic efficacy of GSG in NOD/SCID mice xenografted with DU145 cells

A. Tumor growth inhibition. Mice were dosed (IP) with GSG, [D-Lys $\left.{ }^{6}\right]-G n R H$, gemcitabine (low and high dose) or vehicle (saline). Red arrows indicate the day of 
dosing. Each point represents mean of at least 8 tumor volumes resulting from at least 5 mice \pm SD. $* * *, P<0.001$ vs. controls.

B. AUC $\left(\mathrm{mm}^{3}\right.$ - day) calculated for each treatment group from the tumor volumes of mice. 


\section{Discussion}

Androgen-independent $\mathrm{CaP}$ is a condition in which patients have limited treatment options and therefore expansion of the available therapeutic strategies is critical. The concept of using GnRH agonistic peptides for conjugation to small molecule anticancer drugs such as doxorubicin or docetaxel has been described in the past and the preclinical success of that strategy resulted in the birth of a promising targeted delivery field. ${ }^{20-23,42}$ More importantly, the specific approach has advanced to clinical development stages; AN-152, a GnRH-doxorubicin conjugate has been evaluated in phase I and II trials with promising outcomes in GnRH-R positive patients with breast, endometrial and ovarian cancer. ${ }^{24}$

The anticancer drug chosen for our studies, gemcitabine, has been extensively used for the treatment of solid tumors. Its antiproliferative effect in androgenindependent $\mathrm{CaP}$ cell lines ${ }^{31}$ gave rise to clinical expectations but its benefit in androgen-independent $\mathrm{CaP}$ patients was modest mainly due to its peripheral toxicity. ${ }^{32-34}$ As targeted delivery cannot be based only on a simplified hypothesis that a cancer cell specific ligand will lead to preferable interaction and internalization of the drug in the cancer cell, other important factors should be taken into consideration, such as systemic targeting, tumor penetration, tumor heterogeneity. ${ }^{43}$ For this reason, in this manuscript the focus was not only to enrich the repository of GnRH conjugates with new chemical entities which target GnRH-R positive cancer cells, but also to improve the therapeutic potential of gemcitabine, a very potent drug with poor pharmacokinetic properties. ${ }^{28,29}$ These conjugate molecules would ideally operate as prodrugs of gemcitabine with favorable pharmacokinetic properties by protecting it from its rapid inactivation and provide alternative entrance point into the cell for gemcitabine (through the GnRH-R), a pivotal attribute to overcome resistance to gemcitabine treatment often caused by nucleoside transporter deficiency. ${ }^{29,30}$

[D-Lys ${ }^{6}$ ]-GnRH, a potent GnRH-R agonist was chosen for conjugation to gemcitabine. The D-Lys ${ }^{6}$ position offers an amino side chain appropriate for conjugation reactions since the specific amino acid side chain does not participate in the binding to the GnRH-R. ${ }^{7,8,17} \mathrm{GnRH}$-gemcitabine conjugates containing different linkers and with different gemcitabine conjugation sites were synthesized and evaluated. NMR studies in representative GnRH-gemcitabine conjugates demonstrated that conjugation of gemcitabine to the GnRH peptide does not alter significantly the structural conformation required for successful binding to the GnRHR. Furthermore, the described GnRH-gemcitabine conjugates exhibited high binding affinity to the GnRH-R.

For the in vitro evaluation of the GnRH-gemcitabine conjugates, two androgen-independent $\mathrm{CaP}$ cell lines were used (DU145, PC3) with confirmed expression of GnRH-R. Among the synthesized GnRH-gemcitabine conjugates that were assessed with respect to their antiproliferative potential in vitro, $3 \mathrm{G}_{2}$, GSG and $\mathrm{GSG}_{2}$ exhibited the most prominent effects, similar to those of gemcitabine. Selected molecules $\left(3 \mathrm{G}_{2}\right.$ and $\left.\mathrm{GSG}\right)$ were then evaluated in pharmacokinetic animal experiments due to superior stability in cell culture media. Although the criterion of stability in cell culture might seem arbitrary, the rapid cleavage of these analogues was not a desirable property since ultimately some level of stability would be necessary in order for the conjugates to "present" themselves to the site of action (cancer cell). Administration of GSG in mice for pharmacokinetic evaluation, when compared to administration of gemcitabine or $3 \mathrm{G}_{2}$, resulted in more sustained levels of gemcitabine in blood, indicating potential for enhanced efficacy. Moreover, less $\mathrm{dFdU}$ was produced after administration of GSG compared to administration of 
gemcitabine or $3 \mathrm{G}_{2}$ suggesting that $\mathrm{GSG}$ renders gemcitabine less vulnerable to rapid inactivation. This finding led to the selection of GSG as the lead compound of the current study. The sustained levels of gemcitabine and reduced levels of $\mathrm{dFdU}$ in blood after GSG administration was further confirmed in tissue distribution experiments in mice bearing xenografts. Moreover, GSG, which was shown to be active in antiproliferative assays, could be delivered to the tumor site at appreciable levels. It should be noted that our tumor measurements were based on homogenization of the whole tumor and presumably lack some important information regarding drug intratumoral levels (e.g. measurements at different parts of a tumor might be affected by differences in interstitial fluid pressure).

The protective effect of GSG was further supported by cell uptake experiments where incubation of GSG in DU145 cells suggested that GSG enters the cell and releases gemcitabine in a relatively slow rate, leading to sustained intracellular gemcitabine levels combined with lower levels of dFdU when compared to incubation with gemcitabine. Although passive diffusion of GSG cannot be ruled out, preincubation of DU145 cells with [D-Lys ${ }^{6}$ ]-GnRH limited GSG cell uptake, suggesting a key role of the GnRH-R in the selective cellular entry of GSG.

The efficacy of GSG was evaluated in an in vivo xenograft animal model. GSG treatment was well tolerated (no morbidity or significant changes in body weight during the course of the experiment) and was efficacious in inhibiting tumor growth when compared to gemcitabine or $\left[\mathrm{D}-\mathrm{Lys}{ }^{6}\right]-\mathrm{GnRH}$ at the same molar dose, which were not significantly different from the vehicle. As in previously published reports, ${ }^{44-46}$ gemcitabine efficacy was achieved at a dose exceeding $100 \mathrm{mg} / \mathrm{kg}$ (120 $\mathrm{mg} / \mathrm{kg}$ ) for the specific animal model and dosing scheme. Since GSG efficacy was achieved with a significantly lower dose when compared to gemcitabine (approximately 25 times), it can be suggested that GSG administration might have advantages in comparison to gemcitabine with respect to off target toxicity.

Although the exact mechanism of action for the efficacy achieved with the GSG has not been fully delineated, it should be emphasized that a strong component that adds to the efficacy of GSG is the enhanced exposure of gemcitabine following dosing combined with a decrease in circulating levels of the inactive metabolite $(\mathrm{dFdU})$. As was recently demonstrated by Frese $e t a l^{47}$, approaches which favorably alter gemcitabine's biodistribution properties (e.g., enhanced intratumoral concentration) have important implications for the treatment of a variety of tumors. In projecting on GSG's possible clinical use, we are encouraged to continue to evaluate it further at the preclinical level, anticipating that GSG (as a prodrug) could ultimately lead to significant reduction of gemcitabine's effective dose and adverse effects. Moreover GSG could also be applied to other types of cancer that have been confirmed to express the GnRH-R and are sensitive to gemcitabine treatment such as breast, ovarian, bladder and pancreatic cancers. ${ }^{24,26}$

In conclusion, the lead compound presented in this manuscript, GSG, shows a potent anticancer effect that appears to be associated with a dual mode of action: 1) improved efficacy due to reduced metabolic inactivation of gemcitabine and 2) targeted delivery to cancer cells over-expressing the GnRH-R. We believe that the work presented herein could lead to valuable insights associated with gemcitabine treatment and possibly improve the therapeutic options of androgen independent $\mathrm{CaP}$ patients. 


\section{Experimental Procedures}

Chemicals. Gemcitabine was purchased from Carbosynth Limited (Compton, Berkshire, UK). [Des-Gly ${ }^{10}$, D-Ala ${ }^{6}$, Pro-NHEt ${ }^{9}$ GnRH was purchased from Bachem (Bachem AG, Bubendorf, Switzerland). Fmoc-protected aminoacids were purchased from CBL (CBL Patras, Patras, Greece). HATU ((O-(7-azabenzotriazol-1-yl)$N, N, N^{\prime}, N^{\prime}$-tetramethyluronium hexafluorophosphate), and $\mathrm{HOBt}$ (1hydroxybenzotriazole) were purchased from Neosystem Laboratoire (Neosystem Laboratoire, Strasbourg, France). Triisopropylsilane (TIS), $N, N$ diisopropylethylamine (DIPEA), trifluoroacetic acid (TFA), and piperidine were purchased from Merck-Schuchardt (Merck-Schuchardt, Darmstadt, Germany). $N, N$ Dimethylformamide (DMF) was distilled over ninhydrin and stored under preactivated molecular sieves 4A. N,N'-Diisopropylcarbodoimide (DIC) was purchased from Sigma-Aldrich (Sigma-Aldrich Chemie GmbH, Munich, Germany). Deuterated solvents were purchased from Deutero (Deutero $\mathrm{GmBH}$, Kastellaun, Germany). Ammonium acetate, formic acid and 3-(4,5-dimethylthiazol-2-yl)-2,5diphenyl-tetrazolium bromide (MTT) were purchased from Sigma-Aldrich (SigmaAldrich Chemie GmbH, Munich, Germany). Acetonitrile (ACN, LC-MS grade) was purchased from Fisher Scientific (Fisher Scientific, Loughborough, UK). Water (LCMS grade) was purchased from Carlo Erba (Carlo Erba, Milan, Italy).

Synthesis of GnRH-gemcitabine conjugates. [D-Lys $\left.{ }^{6}\right]-\mathrm{GnRH}$ was synthesized manually by the classical method of solid phase peptide synthesis. ${ }^{48}$ Details for the synthesis of $3 \mathrm{G}, 3 \mathrm{G}_{2}, \mathrm{GSG}, \mathrm{GSG}_{2}$ (Department of Chemistry, University of Ioannina) are presented in the Supporting Information.

Nuclear Magnetic Resonance (NMR) based mapping of possible changes induced in the environment of [D-Lys $\left.{ }^{6}\right]-G n R H$ upon gemcitabine conjugations. To assess the chemical perturbation induced in the environment of [D-Lys ${ }^{6}$-GnRH upon conjugation of the gemcitabine variants, NMR spectroscopy was used. All the NMR spectra were recorded on a Bruker AV-500 spectrometer (Bruker Corporation, Billerica, MA, USA) equipped with a cryoprobe. The NMR samples were prepared by dissolving the solid material in $\mathrm{H}_{2} \mathrm{O} / \mathrm{D}_{2} \mathrm{O}(90: 10)$ at a concentration of $5 \mathrm{mM}$. 2D ${ }^{1} \mathrm{H}-$ ${ }^{1} \mathrm{H}$ TOCSY (Total Correlation Spectroscopy) 1 and $2 \mathrm{D}{ }^{1} \mathrm{H}-{ }^{1} \mathrm{H}$ NOESY (Nuclear Overhauser Effect Spectroscopy) experiments were performed for [D-Lys ${ }^{6}$ ]-GnRH, $3 \mathrm{G}$ and GSG, at $298 \mathrm{~K}$ using standard Bruker pulse sequences. For water suppression excitation, sculpting with gradients was used. The mixing time for TOCSY spectra was $80 \mathrm{~ms}$. Mixing times for NOESY experiments were set to 100, 200, 350 and 400 $\mathrm{ms}$ to determine NOE build-up rates. A mixing time of $350 \mathrm{~ms}$ provided sufficient cross-peak intensity without introducing spin-diffusion effects in the 2D - NOESY.

Binding to the human GnRH-R. Radioiodination of DTyr ${ }^{6}-\mathrm{His}^{5}-\mathrm{GnRH}$, preparation of membrane homogenates from HEK 293 cells stably expressing the GnRH-R and binding of the GnRH-gemcitabine conjugates to the human GnRH-R was performed as described before. ${ }^{49,50}$ In brief, aliquots of diluted membrane suspension $(50 \mu \mathrm{L})$ were added into tubes containing buffer $\mathrm{B}(25 \mathrm{mM}$ HEPES containing $1 \mathrm{mM} \mathrm{CaCl}, 10 \mathrm{mM} \mathrm{MgCl}_{2}, 0.5 \%$ BSA, pH 7.4 at $4^{\circ} \mathrm{C}$ ) and $100,000-$ $120,000 \mathrm{cpm}\left[{ }^{125} \mathrm{I}\right]-\mathrm{DTyr}{ }^{6}-\mathrm{His}^{5}-\mathrm{GnRH}$ with or without increasing concentrations of GnRH-gemcitabine conjugates, gemcitabine, leuprolide, or [D-Lys ${ }^{6}$ ]-GnRH in a final volume of $0.2 \mathrm{~mL}$. The mixtures were incubated at $4{ }^{\circ} \mathrm{C}$ for $16-19 \mathrm{~h}$ and then filtered using a Brandel cell harvester through Whatman GF/C glass fiber filters, presoaked for $1-2 \mathrm{~h}$ in $0.5 \%$ polyethylenimine at $4{ }^{\circ} \mathrm{C}$. The filters were washed four times with 
$1.5 \mathrm{~mL}$ of ice-cold $50 \mathrm{mM}$ Tris- $\mathrm{HCl}, \mathrm{pH} 7.4$ at $4^{\circ} \mathrm{C}$. Filters were assessed for radioactivity in a gamma counter (LKB Wallac 1275 minigamma, 80\% efficiency). The amount of membrane used was adjusted to ensure that the specific binding was always equal to or less than $10 \%$ of the total concentration of the added radioligand. Specific $\left[{ }^{125} \mathrm{I}\right]$-DTyr ${ }^{6}-\mathrm{His}^{5}-\mathrm{GnRH}$ binding was defined as total binding less nonspecific binding in the presence of $1000 \mathrm{nM}$ triptorelin (Bachem, Germany). Data for competition binding were analyzed by nonlinear regression analysis, using GraphPad Prism 4.0 (GraphPad Software, San Diego, CA). IC $\mathrm{I}_{50}$ values were obtained by fitting the data from competition studies to a one-site competition model.

Cell Cultures. The androgen-independent CaP cell lines DU145 and PC3 used in this study were authenticated by STR (short tandem repeat) profiling (Microsynth AG, Balgach, Switzerland). Cells were maintained in RPMI (Roswell Park Memorial Institute) medium, containing glutamine and supplemented with $10 \%$ Fetal Bovine Serum (FBS), penicillin $(100 \mathrm{U} / \mathrm{mL})$ and streptomycin $(100 \mathrm{mg} / \mathrm{mL})$ at $37{ }^{\circ} \mathrm{C}$ and $5 \%$ $\mathrm{CO}_{2}$.

Cell Growth Assay. Cells were plated at a density of $5 \times 10^{3}$ cells per well on 96-well plates. After $24 \mathrm{~h}$ incubation $\left(37{ }^{\circ} \mathrm{C}, 5 \% \mathrm{CO}_{2}\right)$, the cell medium was removed, and compounds were added at selected concentrations (10-20,000 nM), followed by incubation for $72 \mathrm{~h}$. The medium was then removed and the MTT solution $(0.3$ $\mathrm{mg} / \mathrm{mL}$ in PBS) was added to cells for $3 \mathrm{~h}$, after which the MTT solution was removed and the formazan crystals were dissolved in $100 \mu \mathrm{L}$ DMSO. The optical density was measured at $570 \mathrm{~nm}$ and a reference wavelength of $650 \mathrm{~nm}$ using an absorbance microplate reader (SpectraMax 190, Molecular Devices, Sunnyvale, CA, USA). The $50 \%$ cytostatic concentration $\left(\mathrm{IC}_{50}\right)$ was calculated based on a fourparameter logistic equation using SigmaPlot 12 software (Systat Software, San Jose, CA, USA). Each point was the result of three experiments performed in triplicate.

Western Blot Assay. Cells were lysed in RIPA lysis buffer $(20 \mathrm{mM}$ Tris- $\mathrm{HCl}$ at $\mathrm{pH} 7.5,150 \mathrm{mM} \mathrm{NaCl}, 1 \mathrm{mM} \mathrm{Na} \mathrm{N}_{2}$ EDTA, $1 \% \mathrm{NP}-40,1 \%$ sodium deoxycholate) and Protease Inhibitor Cocktail (Roche, UK). Protein concentration was determined using the Pierce ${ }^{\circledR}$ BCA assay kit (Pierce, Rockford, IL, USA) according to the manufacturer's specifications. Protein isolated from the cell lysate (approximately 50 $\mu \mathrm{g}$ of protein/cell line), along with $1 \mathrm{x}$ NuPAGE ${ }^{\circledR}$ Sample Reducing agent and $1 \mathrm{x}$ NuPAGE $^{\circledR}$ LDS Sample Buffer were separated by SDS page and transferred to polivinylidene difluoride (PVDF) membranes. The membranes were then blocked in $5 \%$ non-fat dry milk in TBS-T buffer for $1 \mathrm{~h}$ at room temperature and were then incubated overnight at $4{ }^{\circ} \mathrm{C}$ with 1:500 dilution of rabbit polyclonal primary antibody against GnRH-R1 (Proteintech, UK). This process was followed by another incubation for $1 \mathrm{~h}$ at room temperature with the secondary anti-rabbit horseradish peroxidase-conjugated antibody (Proteintech, UK) at a 1:5000 dilution and visualized by Enhanced Chemiluminescence (ECL) (GE Healthcare, UK). For normalization of protein concentration, the rabbit polyclonal antibody COX4I2 (Proteintech, UK) was used.

Characterization and quantitative analysis of GnRH-gemcitabine conjugates, gemcitabine and $\mathrm{dFdU}$ by Liquid Chromatography-Mass Spectrometry (LC-MS/MS). For the identification and quantification of gemcitabine, dFdU and GnRH-gemcitabine conjugates, LC-MS/MS methodologies were developed and validated as described previously. ${ }^{51}$ HPLC was performed using a Dionex Ultimate 3000 system (Dionex Corporation, Germering, Germany) equipped with three pumps (two for nano and one for micro LC), a temperature controlled column compartment and an autosampler. A C18 column (Agilent, ZORBAX Eclipse, 
$4.6 \times 150 \mathrm{~mm}, 5 \mu \mathrm{M}$ ) was used at a flow rate of $1 \mathrm{~mL} / \mathrm{min}$ for the separation of analytes of interest. The mobile phase consisted of A: 10\% ACN, 90\% water, $2 \mathrm{mM}$ ammonium acetate, and $0.1 \% \mathrm{FA}$ and $\mathrm{B}$ : $90 \% \mathrm{ACN}, 10 \%$ water, $2 \mathrm{mM}$ ammonium acetate, and $0.1 \%$ FA. Mass spectrometry was performed on an API 4000 QTRAP LC-MS/MS system fitted with a TurbolonSpray source and a hybrid triple quadrupole/linear ion trap mass spectrometer (Applied Biosystems, Concord, Ontario, Canada).

Determination of intracellular concentrations of GSG, gemcitabine, and dFdU. Cells (DU145) were plated in 6-well plates at a density of $2 \times 10^{6}$ cells/well. Cells were then incubated with GSG or gemcitabine $(10 \mu \mathrm{M})$ for selected time points $(1 \mathrm{~h}, 4 \mathrm{~h}, 8 \mathrm{~h})$. Incubations were terminated by removing the medium and washing the cells twice with ice cold PBS to remove unbound gemcitabine or GSG. The cells were then lysed by adding an ice cold solution of ACN-Water (3:2) and scraping the cell monolayer. Samples were subsequently vortexed, sonicated and centrifuged for three minutes at 16,060 g (Heraeus Biofuge Pico microcentrifuge, Thermo Scientific, Bonn, Germany). The supernatants were collected, evaporated and stored at $-20{ }^{\circ} \mathrm{C}$ until the day of analysis. Intracellular accumulation of GSG, gemcitabine and $\mathrm{dFdU}$ was determined by LC-MS/MS analysis using a stable internal standard as well as gemcitabine and dFdU standards for the construction of analytical standard curves.

In vivo pharmacokinetics and tissue distribution. All animal procedures were approved by the Bioethical Committee of the Institution on the basis of the European Directive 86/609 on the protection of animals used for experimental purposes. For pharmacokinetic studies, animals at the age of 10-12 weeks were weighed and fasted overnight before dosing $(n=5$ per group, male $C 57 \mathrm{BL} / 6 \mathrm{~N}$ inbred strain obtained from Charles River, Calco, Italy). Dosing solutions of GnRH conjugates $(10 \mathrm{mg} / \mathrm{kg}$ or $6.3 \mu \mathrm{mol} / \mathrm{kg})$ or an equimolar dose of gemcitabine (1.65 $\mathrm{mg} / \mathrm{kg}$ ) in saline were administered intraperitoneally (IP). A serial tail bleeding protocol was used for the collection of blood samples. Blood samples $(10 \mu \mathrm{L})$ were collected at selected time points $(0.25 \mathrm{~h}, 0.5 \mathrm{~h}, 1 \mathrm{~h}, 2 \mathrm{~h}, 4 \mathrm{~h}, 6 \mathrm{~h}, 8 \mathrm{~h})$ in tubes containing $40 \mu \mathrm{L}$ citric acid $(0.1 \mathrm{M}, \mathrm{pH} 4.5)$ and stored at $-80{ }^{\circ} \mathrm{C}$ until sample extraction. Samples were prepared for quantification by protein precipitation and evaporation. Gemcitabine and $\mathrm{dFdU}$ were quantified by LC-MS/MS analysis.

For tissue distribution studies, NOD-SCID (Non-Obese Diabetic/Severe Combined ImmunoDeficiency) mice (Charles River, Calco, Italy) at the age of 8-10 weeks were injected in the flank with $3 \times 10^{6}$ DU145 cells suspended in $200 \mu \mathrm{L}$ RPMI supplemented with $10 \%$ FBS. When tumors reached a volume of $300-400 \mathrm{~mm}^{3}$ (approximately 4 weeks after xenotransplatation) animals $(n=5)$ were weighted and fasted overnight $(12 \mathrm{~h})$ before dosing. Dosing solutions of GSG $(6.3 \mu \mathrm{mol} / \mathrm{kg}$ or $10 \mathrm{mg} / \mathrm{kg})$ or equimolar dose of gemcitabine $(1.65 \mathrm{mg} / \mathrm{kg})$ in saline were administered intraperitoneally (IP). Blood samples $(200 \mu \mathrm{L})$ were collected by cardiac puncture under isoflurane anesthesia at selected time points $(1 \mathrm{~h}, 4 \mathrm{~h}, 8 \mathrm{~h}, 24 \mathrm{~h})$ in $1.5 \mathrm{~mL}$ tubes containing $800 \mu \mathrm{L}$ citric acid $(0.1 \mathrm{M}, \mathrm{pH} 4.5)$. Tumors were removed after sacrificing the animals following anesthesia by isoflurane and cervical dislocation and were washed with PBS, weighed and placed at $-80{ }^{\circ} \mathrm{C}$ until analysis. For LC-MS/MS analysis, tumors were homogenized in sodium citrate, $0.1 \mathrm{M}, \mathrm{pH} 4.5$ (1g tissue weight: $4 \mathrm{~mL}$ of buffer). Gemcitabine, GSG and dFdU were quantified by LC-MS/MS.

In vivo tumor growth inhibition of GSG, gemcitabine, and [D-Lys ${ }^{6}$ ]GnRH. NOD/SCID (Non-Obese Diabetic/Severe Combined ImmunoDeficient) mice were injected in each flank approximately $3 \times 10^{6}$ DU145 cells in RPMI 1640 medium, 10\% FBS. Pharmacologic treatment was initiated when tumors reached a 
volume of $200-300 \mathrm{~mm}^{3}$. GSG $(18.8 \mu \mathrm{mol} / \mathrm{kg}$ or $30 \mathrm{mg} / \mathrm{kg})$ or equimolar doses of [DLys $\left.^{6}\right]$-GnRH $(22.6 \mathrm{mg} / \mathrm{kg})$ or gemcitabine $(4.9 \mathrm{mg} / \mathrm{kg})$ as well as an efficacious dose of gemcitabine $(454.5 \mu \mathrm{mol} / \mathrm{kg}$ or $120 \mathrm{mg} / \mathrm{kg})$ were dosed IP in saline solutions at days $0,3,6,9$ based on a previously described dosing scheme. ${ }^{46}$ Control mice received injections of saline. Tumors growth was monitored every three days by caliper measurements and volumes were calculated based on the formula: $\mathrm{V}=\pi \mathrm{x} \mathrm{D} \mathrm{x}$ $d^{2} / 6$, (D and $d$ represent the larger and smaller diameters of the tumors, respectively). The experiment was terminated after 30 days by euthanizing the animals.

Statistical Analysis. The results presented herein are expressed as mean $\pm \mathrm{SD}$. Statistical analyses were performed by the SigmaPlot 12 software. Statistical significance was determined by using Student's $t$ test.

\section{Acknowledgments}

The authors would like to thank A.G.Leventis foundation and the General Secretariat for Research \& Technology of the Greek Ministry of Education (LS71682/17156/6.12.10) for funding. RM acknowledges support from the MRC and National Research Foundation of South Africa, and the Universities of Pretoria and Cape Town.

\section{Supporting Information}

General methods, experimental details for the synthesis of compounds 2-5 and bioconjugates $\mathbf{3 G}, \mathbf{G S G}, \mathbf{3 G}_{\mathbf{2}}, \mathbf{G S G}_{\mathbf{2}}$. Characterization of GnRH-gemcitabine conjugates $\mathbf{3 G}, \mathbf{3 G}_{\mathbf{2}}, \mathbf{G S G}_{\mathbf{2}}$ by Mass Spectrometry. This information is available free of charge via the Internet at http://pubs.acs.org/.

\section{Abbreviations}

$\mathrm{CaP}$, prostate cancer; GnRH-R, Gonadotropin Releasing Hormone-Receptor; GnRH, Gonadotropin Releasing Hormone; dFdU, 2, 2'- difluorodeoxyuridine; ACN, acetonitrile

\section{References}

(1) Jemal, A., Bray, F., Center, M. M., Ferlay, J., Ward, E., and Forman, D. (2011) Global cancer statistics. CA. Cancer J. Clin. 61, 69-90.

(2) Nelson, W. G., De Marzo, A. M., and Isaacs, W. B. (2003) Prostate Cancer. $N$. Engl. J. Med. 349, 366-381.

(3) Miyamoto, H., Messing, E. M., and Chang, C. (2004) Androgen deprivation therapy for prostate cancer: Current status and future prospects. The Prostate 61, 332-353.

(4) Labrie, F. (1995) Endocrine therapy of prostate cancer: optimal form and timing. J. Clin. Endocrinol. Metab. 80, 1066-1071.

(5) Limonta, P., and Manea, M. (2013) Gonadotropin-releasing hormone receptors as molecular therapeutic targets in prostate cancer: Current options and emerging strategies. Cancer Treat. Rev.

(6) Oudard, S. (2013) Progress in emerging therapies for advanced prostate cancer. Cancer Treat. Rev. 39, 275-289.

(7) Millar, R. P. (2005) GnRHs and GnRH receptors. Anim. Reprod.Sci. 88, 5-28.

(8) Millar, R. P. (2004) Gonadotropin-Releasing Hormone Receptors. Endocr. Rev. 25, 235-275. 
(9) Sealfon, S. C. (1997) Molecular Mechanisms of Ligand Interaction with the Gonadotropin-Releasing Hormone Receptor. Endocr. Rev. 18, 180-205.

(10) Payne, H., and Mason, M. (2011) Androgen deprivation therapy as adjuvant/neoadjuvant to radiotherapy for high-risk localised and locally advanced prostate cancer: recent developments. Br. J. Cancer 105, 1628-1634.

(11) Harrison, G. S., Wierman, M. E., Nett, T. M., and Glode, L. M. (2004) Gonadotropin-releasing hormone and its receptor in normal and malignant cells. Endocr. Relat. Cancer 11, 725-748.

(12) Cheung, L. W. T., and Wong, A. S. T. (2008) Gonadotropin-releasing hormone: GnRH receptor signaling in extrapituitary tissues. FEBS J. 275, 54795495.

(13) Tieva A, Stattin, P., Wikström, P., Bergh, A., and Damber, J. E. (2001) Gonadotropin-releasing hormone receptor expression in the human prostate. The Prostate 47, 276-284.

(14) Morgan, K., Stewart, A. J., Miller, N., Mullen, P., Muir, M., Dodds, M., Medda, F., Harrison, D., Langdon, S., and Millar, R. P. (2008) Gonadotropinreleasing hormone receptor levels and cell context affect tumor cell responses to agonist in vitro and in vivo. Cancer Res. 68, 6331-6340.

(15) Straub, B., Müller, M., Krause, H., Schrader, M., Goessl, C., Heicappell, R., and Miller, K. (2001) Increased incidence of luteinizing hormone-releasing hormone receptor gene messenger RNA expression in hormone-refractory human prostate cancers. Clin. Cancer Res. Off. J. Am. Assoc. Cancer Res. 7, 2340-2343.

(16) Mező, G., and Manea, M. (2010) Receptor-mediated tumor targeting based on peptide hormones. Expert Opin. Drug Deliv. 7, 79-96.

(17) Schally, A. V., and Nagy, A. (1999) Cancer chemotherapy based on targeting of cytotoxic peptide conjugates to their receptors on tumors. Eur. J. Endocrinol. Eur. Fed. Endocr. Soc. 141, 1-14.

(18) Teicher, B. A., and Chari, R. V. J. (2011) Antibody conjugate therapeutics: challenges and potential. Clin. Cancer Res. Off. J. Am. Assoc. Cancer Res. 17, 6389-6397.

(19) Mullard, A. (2013) Maturing antibody-drug conjugate pipeline hits 30. Nat. Rev. Drug Discov. 12, 329-332.

(20) Nagy, A., Schally, A. V., Armatis, P., Szepeshazi, K., Halmos, G., Kovacs, M., Zarandi, M., Groot, K., Miyazaki, M., Jungwirth, A., and Horvath, J. (1996) Cytotoxic analogs of luteinizing hormone-releasing hormone containing doxorubicin or 2-pyrrolinodoxorubicin, a derivative 500-1000 times more potent. Proc. Natl. Acad. Sci. U. S. A. 93, 7269-7273.

(21) Manea, M., Leurs, U., Orbán, E., Baranyai, Z., Öhlschläger, P., Marquardt, A., Schulcz, Á., Tejeda, M., Kapuvári, B., Tóvári, J., and Mezo, G. (2011) Enhanced enzymatic stability and antitumor activity of daunorubicin-GnRH-III bioconjugates modified in position 4. Bioconjug. Chem. 22, 1320-1329.

(22) Aggarwal, S., Ndinguri, M. W., Solipuram, R., Wakamatsu, N., Hammer, R. P., Ingram, D., and Hansel, W. (2011) [DLys(6)]-luteinizing hormone releasing hormone-curcumin conjugate inhibits pancreatic cancer cell growth in vitro and in vivo. Int. J. Cancer J. Int. Cancer 129, 1611-1623.

(23) Sundaram, S., Durairaj, C., Kadam, R., and Kompella, U. B. (2009) Luteinizing hormone-releasing hormone receptor-targeted deslorelin-docetaxel conjugate enhances efficacy of docetaxel in prostate cancer therapy. Mol. Cancer Ther. 8, 1655-1665. 
(24) Engel, J., Emons, G., Pinski, J., and Schally, A. V. (2012) AEZS-108 $\square$ : a targeted cytotoxic analog of LHRH for the treatment of cancers positive for LHRH receptors. Expert Opin. Investig. Drugs 21, 891-899.

(25) Miller, K., Clementi, C., Polyak, D., Eldar-Boock, A., Benayoun, L., Barshack, I., Shaked, Y., Pasut, G., and Satchi-Fainaro, R. (2013) Poly(ethylene glycol)-paclitaxel-alendronate self-assembled micelles for the targeted treatment of breast cancer bone metastases. Biomaterials 34, 3795-3806.

(26) Carmichael, J. (1998) The role of gemcitabine in the treatment of other tumours. Br. J. Cancer 78 Suppl 3, 21-25.

(27) Mackey, J. R., Mani, R. S., Selner, M., Mowles, D., Young, J. D., Belt, J. A., Crawford, C. R., and Cass, C. E. (1998) Functional nucleoside transporters are required for gemcitabine influx and manifestation of toxicity in cancer cell lines. Cancer Res. 58, 4349-4357.

(28) Ueno, H., Kiyosawa, K., and Kaniwa, N. (2007) Pharmacogenomics of gemcitabine: can genetic studies lead to tailor-made therapy? Br. J. Cancer 97, 145-151.

(29) Mini, E. (2006) Cellular pharmacology of gemcitabine. Ann. Oncol. 17, v7v12.

(30) Moysan, E., Bastiat, G., and Benoit, J.-P. (2013) Gemcitabine versus Modified Gemcitabine: a review of several promising chemical modifications. Mol. Pharm. 10, 430-444.

(31) Muenchen, H. J., Quigley, M. M., Pilat, M. J., Lehr, J. E., Brumfield, S. K., Mahoney, M., and Pienta, K. J. (2000) The study of gemcitabine in combination with other chemotherapeutic agents as an effective treatment for prostate cancer. Anticancer Res. 20, 735-740.

(32) Buch-Hansen, T. Z., Bentzen, L., Hansen, S., Hoeyer, M., Jensen, N. V., Saxe, C., and Sengeloev, L. (2010) Phase I/II study on docetaxel, gemcitabine and prednisone in castrate refractory metastatic prostate cancer. Cancer Chemother. Pharmacol. 66, 295-301.

(33) Garcia, J. A., Hutson, T. E., Shepard, D., Elson, P., and Dreicer, R. (2011) Gemcitabine and docetaxel in metastatic, castrate-resistant prostate cancer: results from a phase 2 trial. Cancer 117, 752-757.

(34) Morant, R., Bernhard, J., Maibach, R., Borner, M., Fey, M. F., Thürlimann, B., Jacky, E., Trinkler, F., Bauer, J., Zulian, G., Hanselmann, S., Hürny, C., and Hering, F. (2000) Response and palliation in a phase II trial of gemcitabine in hormone-refractory metastatic prostatic carcinoma. Swiss Group for Clinical Cancer Research (SAKK). Ann. Oncol. Off. J. Eur. Soc. Med. Oncol. ESMO 11, 183-188.

(35) Francia, G., Shaked, Y., Hashimoto, K., Sun, J., Yin, M., Cesta, C., Xu, P., Man, S., Hackl, C., Stewart, J., Uhlik, M., Dantzig, A. H., Foster, F. S., and Kerbel, R. S. (2012) Low-Dose Metronomic Oral Dosing of a Prodrug of Gemcitabine (LY2334737) Causes Antitumor Effects in the Absence of Inhibition of Systemic Vasculogenesis. Mol. Cancer Ther. 11, 680-689.

(36) Pulido, J., Sobczak, A. J., Balzarini, J., and Wnuk, S. F. (2014) Synthesis and Cytostatic Evaluation of 4- $N$-Alkanoyl and 4- $N$ - Alkyl Gemcitabine Analogues. J. Med. Chem. 57, 191-203.

(37) Pasut, G., Canal, F., Dalla Via, L., Arpicco, S., Veronese, F. M., and Schiavon, O. (2008) Antitumoral activity of PEG-gemcitabine prodrugs targeted by folic acid. J. Control. Release Off. J. Control. Release Soc. 127, 239-248.

(38) Dasari, M., Acharya, A. P., Kim, D., Lee, S., Lee, S., Rhea, J., Molinaro, R., 
and Murthy, N. (2013) H-Gemcitabine: A New Gemcitabine Prodrug for Treating Cancer. Bioconjug. Chem. 24, 4-8.

(39) Maiti, S., Park, N., Han, J. H., Jeon, H. M., Lee, J. H., Bhuniya, S., Kang, C., and Kim, J. S. (2013) Gemcitabine-Coumarin-Biotin Conjugates: A Target Specific Theranostic Anticancer Prodrug. J. Am. Chem. Soc. 135, 4567-4572.

(40) Majumdar, S., and Siahaan, T. J. (2012) Peptide-mediated targeted drug delivery. Med. Res. Rev. 32, 637-658.

(41) Guo Zw, Z., and Gallo, J. M. (1999) Selective Protection of 2',2'Difluorodeoxycytidine (Gemcitabine). J. Org. Chem. 64, 8319-8322.

(42) Nagy, A. (2005) Targeting of Cytotoxic Luteinizing Hormone-Releasing Hormone Analogs to Breast, Ovarian, Endometrial, and Prostate Cancers. Biol. Reprod. 73, 851-859.

(43) Kwon, I. K., Lee, S. C., Han, B., and Park, K. (2012) Analysis on the current status of targeted drug delivery to tumors. J. Control. Release Off. J. Control. Release Soc. 164, 108-114.

(44) Jantscheff, P., Esser, N., Graeser, R., Ziroli, V., Kluth, J., Unger, C., and Massing, U. (2009) Liposomal gemcitabine (GemLip)-efficient drug against hormone-refractory Du145 and PC-3 prostate cancer xenografts. The Prostate 69, 1151-1163.

(45) Kanzaki, M., Kakinuma, H., Kumazawa, T., Inoue, T., Saito, M., Narita, S., Yuasa, T., Tsuchiya, N., and Habuchi, T. (2007) Low concentrations of the histone deacetylase inhibitor, depsipeptide, enhance the effects of gemcitabine and docetaxel in hormone refractory prostate cancer cells. Oncol. Rep. 17, 761767.

(46) Boven, E., Schipper, H., Erkelens, C. A., Hatty, S. A., and Pinedo, H. M. (1993) The influence of the schedule and the dose of gemcitabine on the antitumour efficacy in experimental human cancer. Br. J. Cancer 68, 52-56.

(47) Frese, K. K., Neesse, A., Cook, N., Bapiro, T. E., Lolkema, M. P., Jodrell, D. I., and Tuveson, D. A. (2012) nab-Paclitaxel potentiates gemcitabine activity by reducing cytidine deaminase levels in a mouse model of pancreatic cancer. Cancer Discov. 2, 260-269.

(48) Stathopoulos, P., Papas, S., Pappas, C., Mousis, V., Sayyad, N., Theodorou, V., Tzakos, A. G., and Tsikaris, V. (2013) Side reactions in the SPPS of Cyscontaining peptides. Amino Acids 44, 1357-1363.

(49) Laimou, D., Katsila, T., Matsoukas, J., Schally, A., Gkountelias, K., Liapakis, G., Tamvakopoulos, C., and Tselios, T. (2012) Rationally designed cyclic analogues of luteinizing hormone-releasing hormone: enhanced enzymatic stability and biological properties. Eur. J. Med. Chem. 58, 237-247.

(50) Katsila, T., Balafas, E., Liapakis, G., Limonta, P., Montagnani Marelli, M., Gkountelias, K., Tselios, T., Kostomitsopoulos, N., Matsoukas, J., and Tamvakopoulos, C. (2010) Evaluation of a Stable Gonadotropin-Releasing Hormone Analog in Mice for the Treatment of Endocrine Disorders and Prostate Cancer. J. Pharmacol. Exp. Ther. 336, 613-623.

(51) Sofianos, Z. D., Katsila, T., Kostomitsopoulos, N., Balafas, V., Matsoukas, J., Tselios, T., and Tamvakopoulos, C. (2008) In vivo evaluation and in vitro metabolism of leuprolide in mice--mass spectrometry-based biomarker measurement for efficacy and toxicity. J. Mass Spectrom. JMS 43, 1381-1392. 


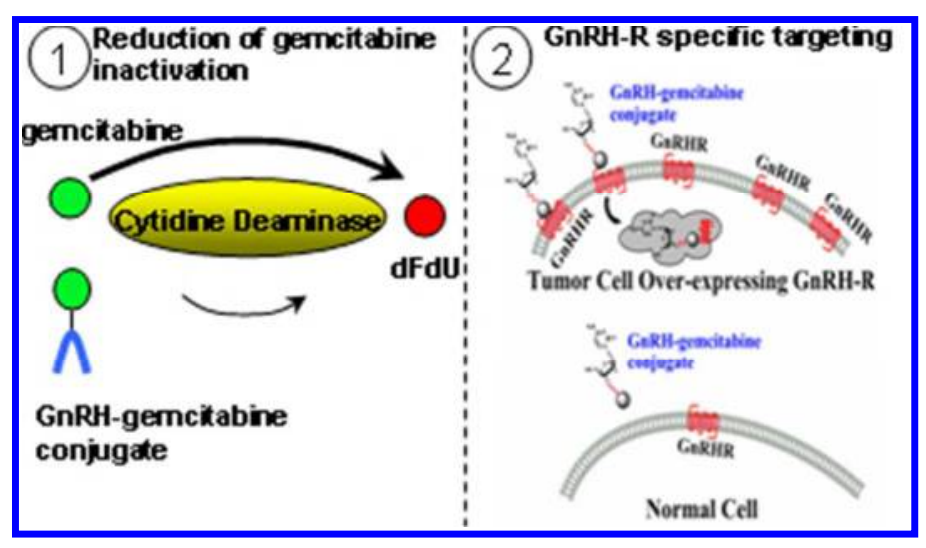

89x50mm (96 x 96 DPI) 